\title{
Investigation of the Effect of Computer Simulation-Based Learning Based on Constructivism in Removing Physics Misconceptions
}

\author{
Zeynab Ghadiri, ${ }^{1,}$ Dariush Norouzi, ${ }^{2}$ and Hashem Fardanesh ${ }^{3}$ \\ ${ }^{1}$ Master of Educational Technology, Allameh Tabatabai University \\ ${ }^{2}$ Associate Professor, Faculty of Psychology and Educational Sciences of Allameh Tabatabai University \\ ${ }^{3}$ Associate Professor of Education at Tarbiat Modarres University \\ "Corresponding author: Zeynab Ghadiri, Master of Educational Technology, Allameh Tabatabai University, E-mail: z_qadiri@yahoo.com
}

Received 2015 May 12; Revised 2015 December 22; Accepted 2015 December 24.

\begin{abstract}
Background: Learners in the correct understanding of physics concepts express their inability, so change in the way of teaching the concepts of physics is necessary; in fact that effective training is learning materials actively involved in the construction of the mind. The aim of the present study is to study the effect of computer simulation based on constructivist approach to remove the misconception in physics course.

Methods: The research procedure is quasi-experimental with pretest- posttest and control group design. The population consists of all male and female secondary school students in Yazd (2009). This research includes 216 students in 2nd grade of high school in Yazd province. The sample is randomly assigned to experimental and control groups. The data collection tool is a questionnaire, using a panel of experts to verify the validity and using Cronbach's alpha as75\% to verify the reliability. For statistical analysis, software SPSS version 16 is used to examine the questions of the t-tests.

Results: The results of the analysis of data using statistical t independent groups showed that. There are significant differences in the effectiveness of computer simulation based on constructivist approach which remove the misconception in physics course ( $\mathrm{df}$ $=160.53, \mathrm{t}=-10.45, \mathrm{sig}=0.00, \mathrm{P}<0.01)$.

Conclusions: Based on the results of the present study, ways of presenting concepts with the help of computer simulation based on constructivist approach is an effective component to remove the misconception in physics course.
\end{abstract}

Keywords: Constructivist, Misconception, Computer Simulation, Learning, Physics

\section{Background}

Physics is the knowledge of discovery and practical application of laws and relationships governing natural phenomena and the basis of this knowledge is based on experimentation. Learners often, due to the inability to properly understand the concepts, consider it to be difficult. This could be because of false ways of presenting the concept. The worst way of presenting the concepts is that learners are forced to memorize without proper understanding of the concepts (1). According to Piaget, learning is the learner's work to absorb and accommodate mental construction (2). Early experience introduction without providing proper context and developing concepts lead to memorization and prevent the development of logical thinking and abstract. Learners learn better when they solve real problems and critically discuss issues with their classmates. Accordingly, teaching physics is based on experimental method and class discussion. This method makes learners active and lasting effect on their minds. Physics teachers try to teach physics to students to correct their ways of thinking (3). However, teaching and learning physics, is always accompanied with misconception in the performance of the students and can cause confusion and failure in solving physics problems. So, it is essential to analyze the roots of mistakes in physics. Falsification of concepts may cause misconception. Some researchers, instead of misconception, proposed the term "raw or simple theory" and some other so-called imagination, but the greatest emphasis is on the word misconceptions or misconception. So, understanding depends on proper ideas and new connections (4). When the students understand the causes of misconceptions and actively cope with the guidance of the teacher as fix and correct it, they will lead to the growth of thinking and insight (5). Also for dealing with abuse misconception not only necessary that teachers be aware of their students' ways of thinking but also it is essential to develop strategies that focus on meaningful learning. Common example of basic science in high schools is power and energy topics. For example, learners believe that power is a property of a material (6), while noting that the troops should be dependent and related to the materials and are not their features. They do not yet understand that the power is constantly intrinsic. Because learners' mistakes take the time of the class, finding 
suitable solutions to analyze and correct training will have great benefits $(7,8)$. In the present study, we investigated and analyzed misconceptions of physics concepts because it is important for teachers to detect misconceptions and to some extent they can adjust their teaching methods based on misconception of students. In fact, awareness of their mental processes will help teachers to try to make the appropriate changes in the way students learn and explore better ways and their close relationship with the real world and the goals of higher education (9). Correct understanding the concepts helps fully understand what students have already learned and helps facilitate what they later learn.

There is no comprehensive definition of power and energy in textbooks. For example, in physics textbooks, energy is defined as the ability to do something, while this definition does not be sufficient for the task. In other words, in addition to the need to define qualitative definition, it is needed to define a quantitative definition and students and even teachers to understand a deep understanding of the concepts. If students learn the power topics, they also learn the energy issues, although they are not of the same issues. So, the diagnosis of misconceptions will help the teacher to identify the types of problems (10). Reviewing the internal and external research in this area indicates that the current misconceptions between students around the world are often similar. The formation of cognitive schemas leads to formation of misconceptions. In any case, our conceptual mistake is due to lack of concentration and carelessness. That's why knowing how to create mental schemas requires multiple investigations (11). Atkinson, in a study titled "misunderstanding possibilities", between the two groups of students from the University of Michigan in the course of a chance of qualifying with two approaches based on teamwork and activity-based teaching, said that students after the activity and group discussion and testing tried to collect, organize and analyze their data and presented the results on the basis of physical models and eventually this group was more successful in overcoming a series of probability. The activity-based approach or work in small groups can help students to overcome the misconceptions (12). Rabbanifard, in a research about misconception and problems associated with trigonometry in high school students, tried to fix it with the help of active methods and participation in learning (13). In order to solve the misconceptions and improve learning, applying new ways of learning and teaching is necessary. Teaching and learning using computer software, learning simulation and instructional design approaches such as constructivism-based approaches enable new ways of learning in recent decades. In the new generation, multimedia technologies and advanced internet based learning simulators invest because creating simulation-based learning is more affordable than previous methods. Kolb believes that the deep intellectual understanding can only be based on empirical findings. In other words, students learn better when they solve real problems and critically discuss issues with their classmates. The value of active learning, training simulations, problem solving and other modern educational pedagogies has been acknowledged by researchers (14).

Sattari and Mohammadi believe that educational computer projects allow the learner to focus on the content of the course and enhance the interactive and dynamic learning and also develop the learners' thinking skills and computer training programs by offering ideas. Research shows the impact of computer-based training programs which focus on learning the content and improving the learning interactive and dynamic thinking skills (15). De Jong defines computer simulation as it: They are computer programs that provide computer model of a system or process'. System or modeling process is usually the source of the natural world and that is usually a simplification of the real world phenomena (16). Balasubramanian believes that simulation is in one of four categories (17):

a) Live simulation (where real people use equipment simulated or dummy in the real world).

b) Virtual simulation (where real people simulated equipment in a simulated world or their environment).

c) Structural simulation (where simulated people use simulated equipment in a simulated environment. Often called as a war game because it resembles the desktop war games in which players lead soldiers and equipment around a table).

d) The role of simulation (where real people play the role of a real job).

Generally, there are two types of simulations: operational and conceptual. Operational simulation primarily designed to teach skills and procedures, while conceptual simulation is based on learning strategy and the specific meaning of a scientific domain. conceptual simulations is focused on the concept of education, principles of physics, genetics, chemistry, botany and ecology (18).

While computer simulations to learn will make teachers ready with better tools to make a credible assessment, they can operate on theories that are learned by the students (19). Yaman, Nerdel and Huber in a study with the topic of impact of educational support on learner's interest when using computer simulation learning, showed that the support that happen in simulation will be developed and will have a positive impact on learning outcomes (20).

Archer in a study titled "Technology and bridge learning to score higher" showed that with using computers 
and the Internet in the classroom and also creating a positive atmosphere in the classroom and schools, academic achievement and higher learning efficiency is achieved (21). Ring staff and Kelly in a qualitative research to examine the impact of technology on learning showed that teachers use technologies such as computers and the Internet to improve the quality of teaching-learning process (22).

Tavares, in his study to evaluate the use of computers in the learning environment in Brazil, showed that the use of computers can enhance learning environments (23). Kilicman, Hassan and Sayed Husain in their research on the theme of using mathematical software in teaching and learning demonstrated the use of software to facilitate the learning process and the achievement of learners (24). Gamboa and Garcia-Souza assessed the impact of information technology on performance and concluded that the frequency of using a computer has a positive impact on students' scores (25). Mayer taught through simulation, in other words, he used simulation to teach the principles of acceleration and speed in physics (26).

Anderson and Lawton achieved three main results: 1) learners like commercial simulation exercises or talk over the speech. 2) There are poor correlation between simulation and actual performance in simulated learning scores. 3) There are little evidence for simulation in presentations or case studies (27). The findings of Najafi show that using computer and the Internet has had an impact on the academic achievement of boys and girls (28). Liu and Katz said that educational multimedia design projects can be a meaningful and harmonious context for the development of high-level thinking skills and the use of students in the learning process and invite them to use technology as a tool (29).

Constructivism is one of the theories of learning. Constructivist approach has been established by the efforts of scientists such as Piaget, Brunner and Vygotsky in the 1970 s and is on the basis of the theory of cognitive psychology (30). Constructivism is becoming a dominant paradigm and approach in the field of education and training. The essence and the cornerstone of this approach is the assumption that knowledge is built inside of the mental processes and not transferred from the outside in the minds of people. One of the important areas of education that has been greatly changed under this approach is the domain of instructional design (as one of the pillars of the teaching and learning process). Constructivism approach spent a lot of time for studying and understanding of its benefits (31). Constructivist learning environments design is very important which consists of a problem, a question or a project as subjective and interpretive center and systems. The purpose of learner is the interpretation or problem- solving or completion of the project. Items related to the issue and sources of information help to understand the problem and offer solutions. Cognitive tools help the students to interpret and work on different aspects of the problem. These tools help students to agree on the meaning of the problem and social support systems help users for using constructivist learning environment (32). There is a tendency in educational models such as dynamic learning, constant learning and cooperative learning (33). Constructivism insists on the fact that learners understand the meanings of the world by building on their own experiences (34).

Constructivism approach emphasizes that the learner actively makes the knowledge. Along with the rise of theory of constructivism, educators decided to design classroom environments based on the principles of constructivism (36). Results of previous studies show that the learning environment that is based on the principles of constructivism is suitable for the classroom. These studies show that learning environments have at least 5 features (37):

1. Personal relationship: This relationship shows the school science with out-of-school experiences.

2. Uncertainty: One of the basic assumptions of the constructivist approach is that knowledge is relative and the result of personal reasons.

3. Talks with students: In constructivist learning environments, teachers are advised to use appropriate instructional strategies to promote class discussions between students as the main activity.

4. Joint supervision: According to the constructivist approach, we want students to have opportunities to become autonomous. Therefore, teachers should provide opportunities for students to be able to monitor the extent of learning.

5. Critical expression: According to critical theory, teachers should be criticism against the objections of students, so that attitudes of students toward learning and training activities grow.

It can be concluded that the design of learning environments and assumptions based on the principles of constructivism approach prepare the students to meet the challenges of modern life (38). Jonassen believes that learning, rather than to be content-based, is based on activity. Teaching methods that are vital to recall information prevent the development of practical knowledge and problem-solving skills needed to override it in the real world (39). In general, teachers play the role of facilitator in the constructivist learning environment and encourage students to grow. They use their old knowledge. So, designing the principles and assumptions of constructivism learning environments are suitable for all-round develop- 


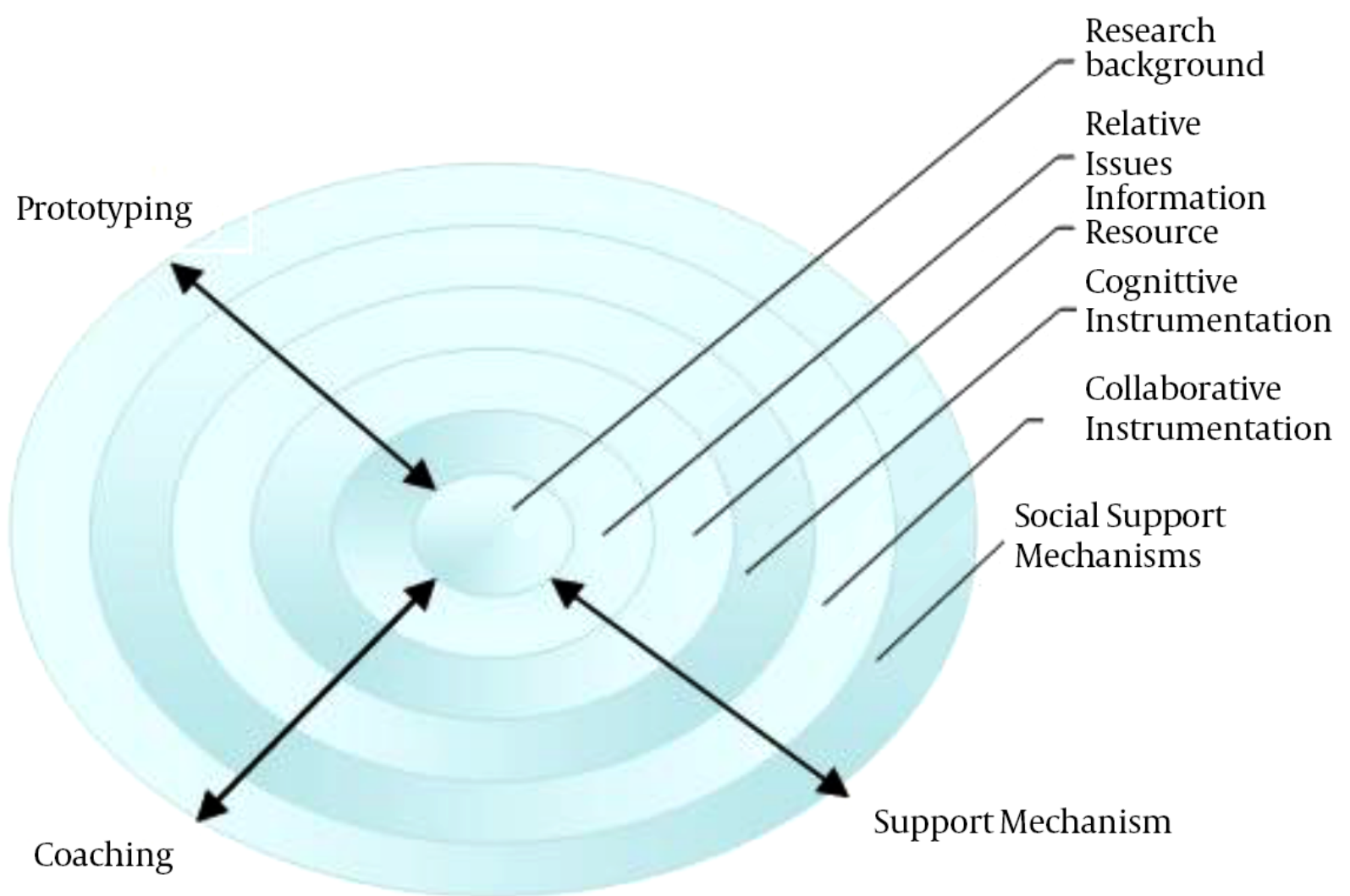

Figure 1. Jonassen Constructivist Design Model (35)

ment of learners and prepare them to meet the challenges of modern life (40). Sheikhzade, in a study to assess the effectiveness of educational software based on constructivism approach, showed that there is a difference between software training based on constructivism approach and group activities as well as the response to questions from the students on the cognitive domain. The results showed that learning through constructivism increases the motivation and problem solving skills (41). Given the above, this study aims to simulate the impact of computer-based learning based on constructivism approach to remove misconceptions of physics. Purpose of this study is to investigate the common conceptual errors in high school physics and computer simulation to evaluate the effectiveness of learning through constructivism approach.

\section{Methods}

The research procedure is quasi-experimental with pre-test and post-test and control group design. The population consists of all male and female secondary school students in Yazd (2009). This research includes 216 students in 2nd grade of high school in Yazd province. To control unwanted variables and minimize confounding variables and to enhance the internal validity of the research, cluster sampling is used. Population is selected with regard to the hierarchy of larger units to smaller units of society (42). In this study, a list of all high schools in Yazd is prepared and then, one region is randomly selected. Then, 4 schools (2 girls and 2 boys) are randomly selected. Two classes are selected from each school (8 classes). Finally, 4 classes as the experimental group and 4 classes as the control group are selected. The study lasted for 4 weeks in 2 sessions of 90 minutes per week (43). In order to implement the above steps, given that the present study aimed to investigate the effect of computer simulation-based learning based on constructivism in removing physics misconceptions, at every level, participants including boys and girls are randomly selected from the population, then randomly divided into two groups. Before running the program, first, a semi-structured interview with 14 physics teachers and 5 physics experts is conducted to see what concepts increase the risk of misconceptions and. Finally, preparing the fi- 
nal questions are conducted (44). The students took pretest and post-test. Data is collected by questionnaire; the validity is confirmed by face validity and content. To assess the reliability of the test, a physics questionnaire is used and the options are the correct and wrong (the correct option 1 , wrong option 0 ). Reliability of the questionnaire is calculated using Cronbach's alpha of \%75. SPSS version of 16 is used for statistical analysis and independent t-test is used to analyze the data. The results of analysis of the data showed a significant difference in the effectiveness of computer simulation-based learning based on constructivism in removing physics misconceptions. So, the use of computer simulation to solve the misconceptions has positive impact. To assess the reliability of computer simulation software, a list of view of two observers in a class is used. In connection with ethical issues of the research, it may be noted that before the implementation of research and questionnaire, participants were satisfied and at the end of the study, participants were informed of the results.

\section{Results}

Depending on the type of research design, pretestposttest with control group is the best statistical method. One-way ANOVA test condition:

1. The homogeneity of the regression slope

2. The homogeneity of variances slope

3. Make a linear relationship between the dependent variable and random

\section{Regression slope homogeneity test}

Based on the results in Table 1, the value of variable grouping interaction with pre-test is $(\mathrm{P}<0.01)$. So, there is a significant difference in regression slope. This assumption is not met and the researcher can not use this test to answer this question. So, the difference between the pre-test and post-test is calculated and we use independent T-test. Implementation of pre-test and post-test in the control group needs random replacement in experimental groups, implementation of pre-test in 2 groups, implementation of operation and implementation of the test in two groups.

Based on Table 2, there is experimental group and the control group in separate gender (female and male).

Based on Table 3, there is no significant relationship between the experimental and control group's score obtained in the pre-test $(\mathrm{P}>0.05)$. In this study, the results of data analysis using independent T-test showed that there is an effective relationship in using computer simulation-based learning based on constructivism in removing physics misconceptions (power and energy topics) among the students (differentiated by gender).
Based on the results in Table 4, there is a relationship in using computer simulation-based learning based on constructivism in removing misconceptions in favor of the experimental group $(\mathrm{df}=160.53, \mathrm{t}=-10.45$, sig $=0.00, \mathrm{P}<$ 0.01 ). In other words, the pre-test and the post-test difference scores of the experimental group is higher than the control group. It means that presenting the issues in using computer simulation-based learning based on constructivism in removing misconceptions is more effective in the experimental group than the control group.

Based on the results in Table 5, There is a significant relationship between the experimental and the control group $(\mathrm{df}=90.02, \mathrm{t}=-10.22, \mathrm{sig}=0.00, \mathrm{P}<0.01)$. In other words, the pre-test and post-test difference scores of the experimental group is higher than the control group. It means that presenting the issues in using computer simulation based learning based on constructivism in removing misconceptions is more effective in the male experimental group than the female control group.

Based on the results in Table 6, There is a significant relationship between the experimental and the control group $\left(\mathrm{df}=76.58, \mathrm{t}_{0}=-60.05, \operatorname{sig}=0.00, \mathrm{P}<0.01\right)$. In other words, the pre-test and post-test difference scores of the experimental group is higher than the control group. It means that presenting the issues in using computer simulation based learning based on constructivism in removing misconceptions is more effective in the female experimental group than the female control group.

\section{Conclusion}

Underpinning a reform movement in in education and changes in educational philosophy is prevailing worldview and view of human beings (45). In fact, education is the host of people who are mentally changed and are expected to join the information age, but in terms of planning and execution, still living in the twentieth century and this duality is the main obstacle to any information on education (46). In the study, education is trying in all societies for achieving the creative citizens familiar with the thinking process and is one of the issues in misconceptions science education. It is assumed, due to the nature of the human mind, that every individual has a variety of misconception. So, the books should not be the only source of education and the purpose of the education should fertilize seeking knowledge through self-education so that they can learn throughout life at any time and in any place. As a result, the revision of the methods, from lecture method to participatory learning methods, and also class discussion and dialogue and group activities so that students play a larger share in the learning process is 
Table 1. A Survey: The Assumption of Homogeneity of the Slope in ANOVA

\begin{tabular}{|c|c|c|c|c|c|}
\hline Change Resource & Total Squares & Degrees of Freedom & The Average Sum of Squares & $\mathbf{F}$ & Significance Level \\
\hline Revised version & 661.160 & 7 & 94.451 & 64.546 & $<0.001$ \\
\hline Fixed amount & 289.124 & 1 & 289.124 & 197.581 & $<0.001$ \\
\hline Grouping & 162.453 & 3 & 54.151 & 197.005 & $<0.001$ \\
\hline Pre-test & 201.071 & 1 & 201.071 & 137.407 & $<0.001$ \\
\hline Variable balance grouping and pre-test & 112.892 & 3 & 37.631 & 25.716 & $<0.001$ \\
\hline Error & 304.371 & 208 & 1.463 & - & - \\
\hline Total & 55830.375 & 216 & - & - & - \\
\hline Total corrected & 965.531 & 215 & - & - & - \\
\hline
\end{tabular}

Table 2. Experimental Group and the Control Group in Separate Gender

\begin{tabular}{lccc}
\hline Gender & Female & Male & Total \\
\hline Group & & & \\
Experimental & 54 & 53 & 107 \\
Control & 54 & 55 & 109 \\
\hline
\end{tabular}

necessary because participating in learning would be enhanced to understand and deal with feedback on what they have learned to refine their understanding $(47,48)$. Thus, in the present day, educational environments which are using particular computer software and computer simulations to learn is rapidly increasing and have made significant progress in the design of learning environments (49) and changes in teaching methods and concepts is essential, especially in physics.

Education is subject to evolution in education-based activities that designs and manufactures products and provides integration (50). So, the present study aimed to investigate the effect of computer simulation-based learning constructivism approach to remove physics misconceptions and indicates that this method has a positive impact and improves learning because human beings learn during the experiment with things. The results of research on discussing the misconceptions and impact of simulation-based approaches show the importance of new approaches and active learning approaches and improve learning. The results of the research is consistent with Kyle Patrick, Ben-zeev, Smith and Rabany fard research results $(5,8,10,13)$. Their research showed that misunderstandings and mistakes take a lot of time of the classroom and work in small groups is useful. The results of data analysis showed that computer simulation-based learning improves learning and will eliminate misconceptions and the result is consistent with the results of Aldridge, Fischler,
Sheikh zadeh and Taylor research (19, 36, 37, 40). Analysis of data from this method of learning showed that the use of computer technology is effective in improving learning and active participation in classrooms and these results are consistent with the results Archer, Ringstaff, Tavares, Kilicman, Hassan, said Husain, Gamboa and Garcia-Suaza studies. They concluded in their research that computer technology, especially software and simulations, improve the quality of teaching process and learning and facilitate the learning process (20-25). Research of Liu, Satari, Mohammadi and Najafi $(15,28,29)$ confirm our results. Anderson and Lawton results also indicate the importance of this method of learning (27). This research that shows the impact of computer simulations to improve learning physics concepts is consistent with Rieber and Kolb research results and suggest a positive association between the use of this learning method and academic achievement $(14,26)$. The results of this study are in line with research results of Aldrich, Dorman, Fraser and Taylor, who insisted on the principles of constructivism $(37,38)$.

According to the strengths of this method, the following is recommended:

- We should guide the learners to learn physics in new ways and they do not have to use a fixed method.

- We should have reflections on misconceptions of students and don't miss them.

-We should connect physics concepts with real and tangible aspects.

- We should help learners discover or create concepts for themselves and avoid direct transmission to them.

- With regard to the merits of constructivism approach in helping to resolve misconceptions, we can use this approach in other subjects with regard to the terms of use.

- Physics should be taught using concrete, practical and relevant examples and also in the form of game, field trips, learning software and computer simulations.

- To understand the concepts, operating in real lab or 
Table 3. Comparison Test of Two Independent Groups in the Pre-Test to Check No Difference

\begin{tabular}{|c|c|c|c|c|c|c|c|c|c|}
\hline \multirow[t]{2}{*}{ Group } & \multicolumn{4}{|c|}{ Descriptive Indexes } & \multicolumn{2}{|c|}{ Homogeneity of Variance Test } & \multicolumn{3}{|c|}{ Comparison Test of Two Independent Groups } \\
\hline & Sample density & Mean & Standard deviation & Standard deviation error & $\mathbf{F}$ & Statistical significant & $\mathrm{t}$ & Degree of freedom & Statistical significant \\
\hline Experiment & 107 & 14.41 & 2.00 & 0.19 & 0.005 & 0.94 & 0.128 & 214 & 0.898 \\
\hline Control & 109 & 14.38 & 2.02 & 0.19 & & & & & \\
\hline
\end{tabular}

Table 4. Comparison the Difference Between Mean Scores of Pre-Test and Post-Test in the Experimental Group and the Control Group

\begin{tabular}{|c|c|c|c|c|c|c|c|c|c|}
\hline \multirow[t]{2}{*}{ Group } & \multicolumn{4}{|c|}{ Descriptive Indexes } & \multicolumn{2}{|c|}{ homogeneity of Variance Test } & \multicolumn{3}{|c|}{ Comparison Test of Two Independent Groups } \\
\hline & Sample density & Mean & Standard deviation & Standard deviation error & $\mathbf{F}$ & Statistical significant & $\mathrm{t}$ & Degree of freedom & Statistical significant \\
\hline Experiment & -2.79 & 2.18 & 0.21 & -2.79 & 29.61 & 0.000 & -10.45 & 160.53 & $<0.001$ \\
\hline Control & -0.30 & 1.15 & 0.11 & -0.30 & & & & & \\
\hline
\end{tabular}

Table 5. Comparison the Difference Between Mean Scores of Pre-Test and Post-Test in the Experimental Group and the Control Group of Male Students

\begin{tabular}{|c|c|c|c|c|c|c|c|c|c|}
\hline \multirow[t]{2}{*}{ Group } & \multicolumn{4}{|c|}{ Descriptive Indexes } & \multicolumn{2}{|c|}{ homogeneity of Variance Test } & \multicolumn{3}{|c|}{ Comparison Test of Two Independent Groups } \\
\hline & Sample density & Mean & Standard deviation & Standard deviation error & $\mathbf{F}$ & Statistical significant & $\mathrm{t}$ & Degree of freedom & Statistical significant \\
\hline Experiment & 53 & -2.80 & 1.49 & 0.20 & 5.38 & 0.02 & -10.22 & 90.03 & $<0.001$ \\
\hline Control & 55 & -0.29 & 0.99 & 0.13 & & & & & \\
\hline
\end{tabular}

Table 6. Comparison the Difference Between Mean Scores of Pre-Test and Post-Test in the Experimental Group and the Control Group of Female Students

\begin{tabular}{|c|c|c|c|c|c|c|c|c|c|}
\hline \multirow[t]{2}{*}{ Group } & \multicolumn{4}{|c|}{ Descriptive Indexes } & \multicolumn{2}{|c|}{ homogeneity of Variance Test } & \multicolumn{3}{|c|}{ Comparison test of two Independent Groups } \\
\hline & Sample density & Mean & Standard deviation & Standard deviation error & $\mathbf{F}$ & Statistical significant & $\mathrm{t}$ & Degree of freedom & Statistical significant \\
\hline Experiment & 54 & -2.79 & 2.72 & 0.36 & 28.38 & $<0.001$ & -6.05 & 76.58 & $<0.001$ \\
\hline
\end{tabular}

the use of computer simulation Software that has been developed with the aim of learning, is useful.

- Teachers are required to attend school and do more research at school. In addition, meetings and classes are arranged to use the experiences of colleagues.

\section{Footnotes}

Authors' Contribution: We ask authors to describe what each author contributed, and these contributions to the work may be published at the editor's discretion. Example: Author Contributions: Study concept and design: Fortes, Melchi, and Abeni. Analysis and interpretation of data: Fortes, Mastroeni, and Leffondre. Drafting of the manuscript: Fortes. Critical revision of the manuscript for important intellectual content: Mastroeni, Leffondre, Sampogna, Melchi, Mazzotti, Pasquini, and Abeni. Statistical analysis: Fortes and Mastoeni. Example: Yoon Kong Loke developed the original idea and the protocol, abstracted and analyzed data, wrote the manuscript, and is guarantor. Deirdre Price and Sheena Derry contributed to the development of the protocol, abstracted data, and prepared the manuscript.
Conflict of Interests: To prevent the information on potential conflict of interest for authors from being overlooked or misplaced, mention this information in the cover letter. Authors must identify any potential financial conflicts of interest before the review process begins. Declared conflict of interest will not automatically result in rejection of paper but the editors reserve the right to publish any declared conflict of interest alongside accepted. The following would generally be regarded as potential conflicts of interest: 1 . direct financial payment to an author for the research or manuscript production by the sponsor of a product or service evaluated in an article. 2. Ownership of shares by an author in the company sponsoring a product service evaluated in an article (or in a company sponsoring a competing product). 3. Personal consultant for companies or other organizations with a financial interest in the promotion of particular health care products and services.

\section{References}

1. Hybrt J, James W. Stigler, Best ideas from the world's teachers for improving education in the classroom 2009. Available from: http: //Bestideas.com/teachers. 
2. Piaget J. Psychology and science of education [In Persian]. Tehran: Tehran University; 1993. pp. 97-117.

3. Robert DR. Misconception in high school physics. Strategies for assisting students overcome their misconceptions in high school physics. J Comp Educ Sci. 2006;46(2):192-205.

4. Wen D, John O. Understand the development of mathematics.J Math Educ. 2001;44(17):74-13.

5. Patrick K, Svafvrd J. Help children learn math [In Persian]. Tehran: Fatemi; 2010.

6. Barrows HS. A taxonomy of problem-based learning methods. Med Educ. 1986;20(6):481-670. doi: 10.1111/j.1365-2923.1986.tb01386.x.

7. Barker V. Beyond appearances students misconceptions about basic chemical ideas. 2nd ed. Londan: Durham University; 2004.

8. Smith Iii JP, diSessa AA, Roschelle J. Misconceptions reconceived: A constructivist analysis of knowledge in transition. J Learn Sci. 1994;3(2):115-63. doi:10.1207/s15327809jls0302_1.

9. Margaret L, Margaret B. National council of teachers of mathematics principles. Standards for school mathematics 2000. Available from: http://www.researchgate.net/profile/MargaretBauman.

10. Ben-Zeev T. The nature and origin of rational errors in arithmetic thinking: Induction from examples and prior knowledge. Cogn Sci. 1995;19(3):341-76. doi:10.1207/s15516709cog1903_3.

11. Abdullah $\mathrm{H}$. examining the misconception of students in mathematics and role in creating and their modification schemas [In Persian]. Tehran: Shahid Beheshti University; 2003.

12. Atkinson RK, Dary SJ, Renkl A, Wortham D. Learning from examples: instructional principlesfrom the worked examples research [Internet] 2002. Available from: http://www.adec.edu/admin/papers/.

13. Rabbanifard A, Zahra G. Check misconception as one of the major obstacles in students' understanding of trigonometric. J Roshd. 2010;30(3):9-23.

14. Kolb D, Alice Y. Experiential learning theory: A dynamic, holistic approach to management learning. J Educ Develop. 2007;11(2):98-107.

15. Sattari S, Mohammadi P. Examine the relationship between uses of information technologies in the educational success of high school students [In Persian]. J Inform Commun Technol Educ. 2011;1(4):81-96.

16. De Jong T. In: Handbook of research on learning and instruction. Mayer, Alexander PA, editors. New York: Routledge; 2011. Instruction based on computer simulation.

17. Balasubramanian N. Games and simulations applied technology teacher angevine middle school United States 2004. Available from: www.innathansworld.com/aboutme/resume/.

18. Ruth C, Clark R, Mayer E. E- learning and the science of instruction [In Persian]. Tehran: Avayenour; 2014.

19. Fischler RB. Encouraging student success through resear. Indiana: Indiana University; 2006.

20. Yaman M, Nerdel C, Bayrhuber $H$. The effects of instructional support and learner interests when learning using computer simulations. Comput Educ. 2008;51(4):1784-94. doi: 10.1016/j.compedu.2008.05.009.

21. Archer F. The link to higher scores in technology and learning. San Francisco: Jossy Bas; 2000. pp. 112-23.

22. Ringstaff C, Kelly L. The learning return on our educational technology investment: A review of findings from research 2013. Available from: http://eric.ed.gov/?id=ED462924.

23. Tavares $M$. The influence of computers in the learning process: A brazilian high school case study. Ohio: Ohio University; 2006.

24. Kilicman A. Teaching and learning using mathematics software: The new challenge. International 2010. Available from: http://www. ScienceDirect.com/SocialandBehaviouralSciences.

25. Gamboa LF, Garcia -Suaza AF. Access to computer and academic achievement. Where is it best: At home or at school? 2010. Available from: http://www.Proac.uff.br/cede/sites/default/.

26. Mayer R. The Cambridge handbook of multimedia learning. New York: Cambridge University; 2005. Multimedia Learning in games, simulations and micro worlds.
27. Anderson PH, Lawton L. Business simulation and cognitive learning: Developments, desires, and future directions. J Simul Gaming. 2009;40(14):13-6

28. Najafi $H$. Impact of information technology on the academic archievement of high school students in Ardabil [In Persian]. J Peyk Noor. 2007;6(3):93-82.

29. Liu M. Enhancing learners cognitive psychology and educational practice. J Theory Pract. 2003;43(4):268-73.

30. Piaget J, Bruner J, Vygotsky L. Perspectives peer influences on cognitive development.J Educ phsychol. 1985;14(6):5-8.

31. Seraji F, Attaran M. E-learning: foundation, design, implementation and evaluation [In Persian]. Hamedan: Buali hamedan University; 2011. pp. 210-4.

32. Fardanesh $\mathrm{H}$, Javdani M, editors. Constructivism approach to instructional design model based on intellectual means [In Persian]. First International Conference on Innovative in Research. 2011 Feb 22; Tehran. Alzahra University; pp. 17-23.

33. Masnavi A. Educational multimedi: a guide to design, production and evaluation of multimedia projects in classroom [In Persian]. Ahvaz: Chamran Univerity; 2014.

34. Fardanesh $\mathrm{H}$, Sheikhi Fini A. An introduction to constructive approach in psychology and pedagogy [In Persian]. J Hum Sci. 2002;7(42):125-46.

35. Jonassen DH. Thinking technology: Towards a constructivist design model. Educ Technol Res Dev. 1994;3(5):83-8.

36. Santrock JW. Educational psychology. New York: McGrawHill; 2012. pp. 407-514.

37. Aldridge JM, Fraser BJ, Taylor PC, Chen CC. Constructivist learning environments in a crossnational study in Taiwan and Australia. Int J Sci Educ. 2000;22(1):37-55. doi:10.1080/095006900289994.

38. Aldridge JM, Dorman JP, Fraser BJ. Use of multitrait- multimethod modeling to validate actual and Preferred forms of the Technologyrich outcomes focused learning environment inventory (TROFLEI) Australian J Educ Dev Psychol. 2004;4(7):110-25.

39. Jonassen D, editor. Constructivist learning environments: Engaging the learner. Agricultural Communicators in Education Conference. 1998 March 5; Northeast Regional. Indiana university; pp. 67-89.

40. Kolb AY, Kolb DA. Experimental learning theory: A dynamic, holistic approach to management learning. J Educ Dev. 2008;17(9):312-7.

41. Sheikhzadeh M, Mohammadi M. Elementary math education software based on constructivism and measures its effectiveness, Computer Research Center of Islamic Sciences [In Persian]. J Educ Innov. 2004;3(9):32-48.

42. Sarmad Z. Research methodology in behavioral sciences [In Persian]. Tehran: Agah; 2009.

43. Meredith G. Qualitative and quantitative research methodology in psychology and pedagogy [In Persian]. Tehran: Shahid Beheshti University; 2003.

44. Fergosen GA, Takan Y. Statistical analysis in psychology and education [In Persian]. Tehran: Arasbaran; 2006.

45. Patriarch A. overcomes obstacles of democratization in math education. $2000 ; 66$

46. Gouya Z. Misconceptions in mathematics [In Persian]. J Math Educ 2002;66(8):23-36.

47. Ajarash $\mathrm{H}$. The effects of computer-aided instruction on educational advancement [In Persian]. J Technol Educ. 2010;5(1):17-24.

48. Yancilap S, Geban O. Effectiveness of using computer assisted supplementary instruction for reaching the concept. J Res Sci Teach. 2008;32(10):1083-109.

49. Sitzmann T. A meta-analytic examination of the instructional effectiveness of computer-based simulation games. Person Psychol. 2011;64(2):489-528. doi: 10.1111/j.1744-6570.2011.01190.x.

50. Chamanara S. Introduction to mathematics teaching methods, based on a structured and Construction [In Persian]. J Math Educ. 2005;81(10):21-31. 